\title{
Effect of food supply on the detoxification in the blue mussel, Mytilus edulis, contaminated by diarrhetic shellfish toxins
}

\author{
Claire Marcaillou $^{1, a}$, Joël Haure ${ }^{2}$, Florence Mondeguer ${ }^{1}$, Anne Courcoux $^{1}$, Béatrice Dupuy ${ }^{2}$ \\ and Christian Pénisson ${ }^{2}$ \\ 1 IFREMER, Dep. Environnement, Microbiologie \& Phycotoxines, rue de l'Ile d'Yeu, BP 21105, 44311 Nantes, France \\ 2 IFREMER, Station conchylicole des Pays de la Loire, Polder des Champs, 85230 Bouin, France
}

Received $1^{\text {st }}$ April 2010; Accepted 30 September 2010

\begin{abstract}
The objective of this study was to identify a possible effect of food on the acceleration of decontamination in blue mussels, Mytilus edulis, containing diarrhetic toxins belonging to the okadaic acid (OA) structural group. An experimental protocol was designed to describe and compare the decontamination kinetics and detoxification rates of naturally OA-contaminated mussels that had either received or not received food for three weeks. The protocol was applied in two trials (in June 2006 and June 2007, called Ker06 and Ker07), conducted one year apart on samples of mussels collected in the same area, at the same season. Okadaic acid (OA), the main lipophilic toxin produced by the toxic alga Dinophysis acuminata, was analysed over the course of the decontamination, in hydrolysed (total OA) and non hydrolysed (free OA) digestive gland extracts, in order to estimate acyl-esters (7-O-acyl-ester derivatives of $\mathrm{OA}$ ) concentrations. OA analyses were also made for toxin presence in biodeposits and in the aqueous phase. Bivalve physiological status was evaluated by biomass measurements (dry weight of flesh) and two biochemical compounds (total lipid and glycogen concentrations). Measured physiological parameters showed that mussels did not suffer under experimental conditions. Both trials showed that the food accelerated the elimination of free and total OA. This effect cannot be attributed to a dilution of the toxin in the tissue, as results expressed in toxin burden led to the same conclusion. The kinetic models of decontamination differed between the two experiments: the model was linear for Ker06, provided that the values corresponding to the first two days were discarded, whereas data fitted a decreasing exponential curve better in Ker07. Detoxification rates increased as the food supply increased. After three weeks of experimentation, the detoxification rates for total OA in Ker06 and Ker07 were 52 and 61\%, respectively, in unfed mussels and 90 and $89 \%$ in fed mussels (with the highest level in Ker07). Comparisons between the free OA and esters showed that detoxification rate was higher for free OA than for esters, whatever the level of food supply. The results of this study suggest that food increase probably accelerates elimination of OA and OA-esters but the latter are eliminated at a lower speed.
\end{abstract}

Key words: Mussel / Feeding / Digestive gland / Depuration / Okadaic acid / Acyl esters / Marine lipophilic biotoxins / Mass spectrometry

Résumé - L'objectif de cette étude est de mettre en évidence un effet éventuel de la nourriture sur la vitesse de décontamination de moules, Mytilus edulis, contenant des toxines diarrhéiques de la famille de l'acide okadaïque (OA). Un protocole expérimental est conçu pour décrire les cinétiques durant 3 semaines d'expérience et comparer les taux de détoxication d'une part chez des moules nourries et d'autre part chez des moules maintenues à jeun. Ce protocole est appliqué sur des moules prélevées au même endroit, à la même saison, en 2006 et 2007 (Ker06 et Ker07). L'acide okadaïque, principale toxine diarrhéique produite par la micro-algue responsable de la toxicité (Dinophysis acuminata) est suivi au cours de la décontamination par l'analyse des extraits de glande digestive hydrolysés (OA total) et nonhydrolysés (OA libre); ceci afin d'estimer les concentrations en acyl-esters (7- $O$-acyl-esters de l'acide okadaïque). Une éventuelle présence de toxine est aussi recherchée dans les bio-dépôts et la phase aqueuse. L'état physiologique de ces bivalves est évalué par des mesures de biomasse (poids sec de chair) et de deux paramètres biochimiques (lipides totaux et glycogène); les résultats relatifs à ces paramètres de condition attestent que les moules n'ont pas souffert du dispositif expérimental. Les deux expériences de décontamination montrent que la nourriture accélère l'élimination de OA libre et de OA total. Cet effet ne peut être attribué à une dilution des toxines dans les tissus car l'expression des résultats en charge toxinique par individu aboutit à la même conclusion. Les modèles de cinétique diffèrent entre les deux expériences : le modèle est linéaire pour Ker06 à condition de ne pas tenir compte des deux premiers jours, alors

a Corresponding author: claire.marcaillou@ifremer.fr 
que pour Ker07, le modèle s'ajuste à une exponentielle décroissante. Le taux de détoxication augmente quand le niveau de nourriture augmente. Ainsi, chez les moules maintenues à jeun, la diminution de OA total après trois semaines d'expérience atteint 52 et $61 \%$ pour respectivement Ker06 et Ker07. Chez les moules nourries, ce taux s'élève à 96 et $93 \%$ respectivement pour Ker06 et Ker07 (avec l'apport le plus élevé de nourriture). Par ailleurs, le taux de détoxication de OA libre est plus élevé que celui des esters quel que soit le niveau de nourriture considéré. Les résultats de cette étude suggère que l'apport de nourriture favoriserait l'élimination de OA et des esters mais que ces derniers s'élimineraient plus lentement.

\section{Introduction}

The shellfish industry is the most productive part of all marine aquaculture in Europe. It relies mainly on bivalve molluscs, which are in increasing demand for both fresh and processed products (Food and Agricultural Organization, Eurostat). Nevertheless, farmed shellfish production is being drastically affected by the development of toxic microalgae. In Europe, economic losses are mainly the result of proliferation of microalgae from the genera Dinophysis spp. When Dinophysis cells proliferate in littoral water, human consumption of contaminated shellfish may result in intoxications with symptoms similar to severe gastroenteritis (diarrhetic shellfish poisoning or DSP). Toxins produced by Dinophysis spp. can be separated into two families of polyether compounds, each of which include several structurally similar molecules: (1) okadaic acid and its analogues and (2) the pectenotoxins. The okadaic acid group, responsible for most DSP outbreaks comprises: okadaic acid (OA), its isomer dinophysistosin-2 (DTX-2) (Hu et al. 1990a) and its methyl derivative, named dinophysistoxin-1 (DTX-1) (Murata et al. 1982), plus the esters of these parent compounds. These esters are divided into two sub-groups according the origin of their discovery. In algal cells, the ester sub-groups such as diol-esters result from the acylation of the carboxyl group of the parent molecules. The first diol-esters were isolated from a Prorocentrum lima culture (Hu et al. 1990b), another dinoflagellate producer of diarrheic toxins. In bivalves, another kind of derivative was discovered: the 7-O acyl esters, so called because their ester bond is engaged in the seventh carbon atom with diverse saturated or unsaturated fatty acid chains. The DTX-1 acyl esters were firstly described in scallops and grouped under the name of DTX-3 (Yasumoto et al. 1985). Later, OA and DTX2 acyl esters were found in Irish mussels (Marr et al. 1992). As they have not yet been detected in the Dinophysis cells and are less toxic than their parent molecules (Yanagi et al. 1989), it has been assumed that these acyl esters are the products of metabolic activity in bivalve digestive glands (Suzuki et al. 1999, 2005). The toxins from the OA family are often referred to as "dinophysistoxins" or "DTXs" in the literature, even though historically the term DTXs refers only to DTX-1, DTX-2 and their acylate analogues. These toxins are likely to be found in the digestive tract of bivalves but, due to the lack of standards, only OA is quantified using a certified standard. The parent molecules (DTX-1,2) are currently quantified in shellfish by making the assumption that they have the same liquid chromatography-mass spectrometry (LC-MS) response as OA. The acylate derivatives are estimated as parent molecules after a hydrolysis step on the extract.

Among commercial bivalves, blue mussels present the highest risk of causing diarrheic shellfish poisoning. From
1978, in the first description of this kind of intoxication, Yasumoto et al. (1978) observed that mussels were more toxic than the scallops and oysters collected in the same area. Later, studies comparing the contamination level of different edible shellfish showed that mussels accumulate DTX more rapidly and intensively than other bivalves (Vale and Sampayo 2002). In a study on the dynamics of contamination, Sidari et al. (1998) highlighted the ability of mussels to select dinoflagellates and their preference for Dinophysis cells.

Shellfish do not remain toxic indefinitely but the time required for depuration is extremely variable. Hence, it is of great interest to find methods to speed up detoxification processes in order to minimize economic losses. Initial attempts to improve depuration time focused on the transplantation of contaminated mussels to an area free of toxic cells and showed promising decontamination rates. In Sweden, Haamer et al. (1990) obtained a decrease in OA concentration of around 50\% over 4 days ( $12 \mu \mathrm{g} 100 \mathrm{~g}^{-1}$ meat per day in mussels). In Italy, with the same technique, the OA concentration diminished from 4.25 to $0.72 \mu \mathrm{g} \mathrm{g}^{-1}$ in mussel digestive glands in 8 days (Poletti et al. 1996), i.e. assuming that DG represented $20 \%$ of the total flesh. However, such transfers are not always possible and sometimes, as seen in Sweden and Norway, decontamination takes place very slowly (Svensson 2003; Duinker et al. 2007). Inshore depuration systems permitting the control of certain parameters, like temperature and food supply, have also been investigated. However, an expected positive effect of temperature on bivalve decontamination was not demonstrated. For example, Dahl and Yndestad (1985) observed that the DTX content decreased in spring when the local water temperature was around $0{ }^{\circ} \mathrm{C}$ and phytoplanktonic biomass was increasing. Like subsequent authors (Lindahl and Hageltorn 1986; Edebo et al. 1988; Haamer et al. 1990), they hypothesised that food plays an essential role in toxin elimination. Additionally, Marcaillou et al. (1993) showed that OA concentration went down faster when the mussels were fed sufficiently with a continuous flux of sea water containing natural phytoplankton than when they were maintained with just a survival ration. In 1999, in an in situ transfer experiment, Blanco et al. studied the influence of different environmental conditions (salinity, temperature, fluorescence, light transmission, mussel body weight) on OA depuration in mussels contaminated by a Dinophysis bloom. They highlighted, using principal component and multiple regression analysis, that fluorescence and light transmission (seston markers) seem to have the most prominent effect on depuration. However, these authors failed in their attempt to quantify the influence of these parameters on the decontamination rates and did not include esters in their analysis. Another experiment on mussel decontamination in sea-water showed that the elimination kinetics of OA and 
DTX-1 were different from those of their acyl esters (DTX-3), supposedly produced by the bivalve (Fernández et al. 1998).

All these previous studies support the hypothesis of a positive effect of food supply on toxin elimination, describing a biphasic kinetic with a rapid first phase and a slow second one. However, no direct evidence has been given and, more recently, authors have challenged this hypothesis.

In 2003, Svensson followed the OA concentration in mussels subjected to three experimental conditions: without food and with two levels of a mixture of non toxic microalgae, over 32 days. This work demonstrated a $50 \%$ decrease in toxin concentration but no significant difference between the mussels that were fed and those that were left unfed; there was also no significant difference between the two microalgae levels. Findings were the same when results were expressed in total OA content of the digestive gland. Subsequently, from data collected in the field, Svensson et al. (2004) recorded a rapid decrease in OA concentration before the occurrence of the diatom bloom. Hence, the authors questioned whether food had a positive effect, and hypothesised that lipid content plays a role in OA elimination. Nevertheless, the results obtained from a laboratory experiment conducted as part of the same study revealed no relation between OA elimination and lipid content in the digestive gland. The OA esters were not investigated in either study.

In 2007, Duinker et al. also contested the positive effect of food using an original approach. They compared the field decontamination of two contaminated mussel populations that differed in age and size. The hypothesis was that younger bivalves would have a faster metabolism and could decontaminate themselves more rapidly than older animals under the same conditions. However, the results, taking into account esterified toxins and variations in the biomass over time, showed that there was no difference in the elimination kinetics between the two mussel age classes. Contrary to what was expected, younger mussels did not depurate faster than older ones. The authors concluded that differences in feeding and metabolic activity did not affect the elimination rate of DTX.

From this review, it is therefore not possible to draw a clear conclusion about the effect of food on detoxification, due to the heterogeneity of the experimental conditions, the diversity of the parameters measured and the high variability of individual results. In the present study, the detoxification issue is reconsidered in an attempt to take into account the recommendations made in these previous studies or the negative results they recorded.

Two decontamination experiments were set up in the same season in two consecutive years, on mussels of same species, with the objective of describing the detoxification kinetics in the presence and absence of food in a controlled system. The mussels studied in these experiments came from an area regularly affected by Dinophysis acuminata, a species known to produce mainly OA and esters that have yet not been individually identified (Marcaillou et al. 2005). However, in contrast to the previous studies, decontamination kinetics were established, separately quantifying free OA and total OA (which includes all esters of OA released after a hydrolysis procedure). Moreover, some physiological parameters were measured in order to evaluate bivalve condition.

\section{Materials and methods}

\subsection{Experimental material}

Mussel sampling. The experiments were performed in 2006 and 2007 and named Ker06 and Ker07, respectively. For both experiments, toxic mussels were collected from a shellfish production area, Kervoyal ("Ker"), located in South Brittany (Atlantic coast) during the increasing phase of Dinophysis acuminata proliferation in June. Approximately $350 \mathrm{~kg}$ of mussels (Mytilus edulis, 4-7 cm size) were harvested by a shellfish farmer on the day when the contamination was expected to be at its highest level. The contamination level estimated a few days before the harvesting was quite similar in 2006 and 2007: around $5 \mu \mathrm{g}$ OA eq. $\mathrm{g}^{-1}$ digestive gland (DG), fresh weight. In this area, mussels are reared on "bouchots" (wooden stakes) and samples were collected at high tide at two-three meters depth. Mussels were transported without prior sorting (so as to limit stress), to an experimental station situated approximately $100 \mathrm{~km}$ from the sampling point. On arrival, the mussels were washed and roughly sorted to discard any coarse waste and dead animals and all the batches were grouped into a single pile. Then, 16 trays were filled with $13-15 \mathrm{~kg}$ of mussels taken at random from the pile. No significant mortality was observed on the day of arrival.

Experimental infrastructure. The experiment was conducted in two $0.8 \mathrm{~m}^{3}$ tanks in which two stacks of four trays of mussels were immersed. Both tanks were supplied with a continuous flow $\left(2.5 \mathrm{~m}^{3} \mathrm{~h}^{-1}\right)$ of subterranean water with the following characteristics: salinity $33-34$, temperature $14-15^{\circ} \mathrm{C}$, $\mathrm{pH}$ 7. This water is highly stable in its physical characteristics, but unsuitable in its crude state for a depuration trial. It was therefore filtered through a biological filter before use $\left(\mathrm{NH}_{4}\right.$ is converted into $\mathrm{NO}_{3}$ which is less toxic for shellfish) and oxygenated in order to precipitate iron (98\% decrease).

Food supply. The experimental station has facilities to continuously produce a large biomass of the diatom Skeletonema costatum, extensively used in aquaculture, in monoculture. The crude subterranean water is perfectly suited to diatom culture, which is done in $80 \mathrm{~m}^{3}$ outdoor tanks and available at an initial concentration of approximately $1 \times 10^{6}$ cell ml$^{-1}$. These fodder algae were delivered into the experimental tanks via a gate regulating the flow. Two food conditions were tested in June 2006 (Ker06): a level of the diatom around $10-15 \times 10^{3}$ cell ml $\mathrm{m}^{-1}$ and a "control" without food. In June 2007 (Ker07), tanks were prepared for three treatments: without food (control tank) or with diatoms at densities of around $10-15 \times 10^{3}$ cell ml ${ }^{-1}$ (Tank A) and $20-30 \times 10^{3}$ cell ml $^{-1}$ (Tank B), corresponding to $1 / 80$ and of $1 / 40$ of the mother culture concentration, respectively. Food retention was monitored indirectly via chlorophyll $a$ measurement at the inlet and outlet of each tank.

\subsection{Methods}

Experimental design and parameters. The two experiments carried out in this study used a very similar protocol. Nevertheless, due to an additional food level in the second trial, the 
number of sampling days was reduced at the beginning in order to adjust the work load to a practical level. Toxin evolution was monitored by chemical analysis of the digestive glands (DG), but the remaining tissues ("meat") were also verified to ascertain whether they contained any toxins. Physiological status was evaluated by measuring condition index and two biochemical parameters representing the main forms of energy storage in mussels (lipid content and glycogen; De Zwaan and Mathieu, in Gosling 1992).

The possibility of toxin release into the growing environment was investigated qualitatively by testing for toxins in the biodeposits and water. Biodeposits consist of a mixture of faeces, pseudo-faeces and some inorganic matter. It was verified that the live algal culture did not sediment on the bottom of the tank. Biodeposit samples were collected on each sampling day during the trial for dry weight estimates and toxin analysis. In order to detect any dissolved toxins, SPATT resin bags (Solid Phase Adsorption Toxin Tracking) were suspended between the tray stacks. Three SPATT bags were removed four times during the experiment (on the sixth, tenth, fifteenth and twentieth days). The efficiency of this technique, inspired by a study in New Zealand (MacKenzie et al. 2004), has previously been established (Fux et al. 2008).

Sample collection and processing. The decontamination monitoring was based on 8 and 6 mussel sampling dates in Ker06 and Ker07, respectively, defined as $T n$, where $n$ indicates the day of sampling. On sampling days, the trays were removed from the tanks and the water drained very slowly to allow the biodeposits to sediment and the collection of an aliquot. To take into account the individual variability, a large mussel sample was prepared on each occasion. For each tank, the procedure was as follows: approximately 15-20 individual mussels were removed at random from each tray and then grouped to form the sample (1.5-2 kg per tank) for parameter measurement. The weight of all samples taken over the course of the trial represented less than $15 \%$ of the total weight of the mussels in each tank. Dead animals were discarded and weighed. For chemical analysis, a sub-sample from the pool of around $1 \mathrm{~kg}$ was then dissected, separating the digestive gland (DG) from the remaining tissues, regarded as residual meat. After draining, the tissues were transferred into tubes for immersion in liquid nitrogen: DG were stored at $-80{ }^{\circ} \mathrm{C}$ and residual meat at $-30{ }^{\circ} \mathrm{C}$ in the laboratory. Water content was calculated for DG and residual meat from an aliquot of these ground homogeneous matrices after freeze-drying. The remaining individuals were used for the condition measurement.

Chlorophyll $\boldsymbol{a}$ monitoring. Water samples were collected at the inlet and outlet of each tank every 3 or 5 days over the course of the experiment. Chlorophyll $a$ concentration was measured by the Lorenzen method (fluorometric determination, Lorenzen and Jeffrey 1980).

Mussel condition. Mortality rate, evolution of dry total meat weight and two biochemical parameters (lipid and glycogen) were used to assess mussel condition. Mortality rates were evaluated from the cumulative weight of dead individuals over the trial period in relation to the initial weight of mussels in each tank. Dry weight was estimated from 90 individuals at the beginning, middle and end of the experiment. This material
(90 pooled individuals) was then used for analysis of total lipid and glycogen concentrations according the methods described by Bligh and Dyer (1959) and Dubois et al. (1956), respectively, with 9 replicates.

Biodeposits. As water release from the biodeposits could not be avoided, the collection of the more or less aqueous sludge could not be quantified. Biodeposits were nevertheless analysed. After decanting, some water was removed, the remaining mud was homogenized and an aliquot was preserved frozen. After thawing, the biodeposit volumes were reduced by centrifugation and an aliquot from the bottom was freeze-dried for water content analysis. Toxin analysis was carried out on 1 to $5 \mathrm{~g}$ of wet deposit, depending on the amount available. Extraction was then conducted in the same way as for tissues. One aliquot was subjected to alkaline hydrolysis for ester detection with the same procedure as that used for digestive glands. Results were expressed in concentration per gram of dry weight.

Toxin extraction and detection. The toxins were extracted from the thawed tissues (digestive gland and residual meat) in accordance with a lab-designed protocol (Mondeguer et al. 2004) validated against certified contaminated standards (AOCS-1 and MUS-2 IBM, NRC, Canada). An extraction was made on a $4 \mathrm{~g}$ aliquot from the homogenate, using 10, 8 and $6 \mathrm{ml}$ of pure acetone. Acetone was favored over methanol for its capacity to extract lipophilic toxins (Mondeguer et al. 2003). The combined acetone layers were topped up to $25 \mathrm{ml}$ and then split into two equal fractions and evaporated to dryness. One fraction was used for alkaline hydrolysis for detection of okadaic acid derivatives (diol or acyl esters). The dry residue was re-suspended in $1 \mathrm{ml}$ pure acetone, and $125 \mu \mathrm{l}$ $\mathrm{NaOH}$ water solution $(2.5 \mathrm{~N})$ were added. After one night at room temperature, the reaction was neutralized with $125 \mu \mathrm{l}$ $\mathrm{HCl}(2.5 \mathrm{~N})$ and the solvent was evaporated. This procedure was previously compared with the usual one $\left(75^{\circ} \mathrm{C}\right.$ for $\left.40 \mathrm{~min}\right)$ on a sample with 3 replicates. The results were as follows: $3.9 \pm 0.6 \mu \mathrm{g} \mathrm{g}^{-1}$ and $4.2 \pm 0.3 \mu \mathrm{g} \mathrm{g}^{-1}$ for room temperature and $76{ }^{\circ} \mathrm{C}$ for $40 \mathrm{~min}$, respectively, and treatments were not significantly different $(t$-test $p>0.05)$. Our procedure could therefore be used to save time by reducing the number of sample manipulations. The dry hydrolyzed and non-hydrolyzed extracts were dissolved in $10 \mathrm{ml}$ hexane/chloroform (50/50 vol.). The solid-phase extraction process was automated on an ASPEC Xli robotized unit (Gilson) fitted with a silica cartridge (Lichrolut Si $500 \mathrm{mg}, 40-60 \mu \mathrm{m}$ ), conditioned with $15 \mathrm{ml}$ chloroform and then $10 \mathrm{ml}$ hexane. Then, $1.5 \mathrm{ml}$ of the extract was eluted with a mixture of methanol/chloroform $(50 / 50$ vol.). Detection and quantification were carried out by HPLC coupled with ion trap mass spectrometer (LC-MS), under the following conditions: column and pre-column: Kromasil: C18 $(250 \mathrm{~mm} \times 2.0 \mathrm{~mm}$, ID $0.5 \mu \mathrm{m})$; temperature: $40^{\circ} \mathrm{C}$; isocratic mobile phase: acetonitrile/water $+0.1 \%$ trifluoroacetic acid,

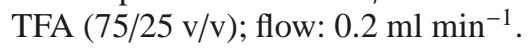

The ThermoFinnigan LCQ Classic ion trap mass spectrometer (San Jose, CA, USA) was operated in the electrospray positive ion mode. The source voltage was maintained at $4.5 \mathrm{kV}$. The heated capillary was operated at $120.5^{\circ} \mathrm{C}$, and the sheath and auxiliary gases were set at 44 and 15 (arbitrary units), respectively. The instrument was set to acquire 3 microscans with a maximum injection time of $300 \mathrm{~ms}$ per 
microscan. Ultrahigh-purity helium was used as the buffer gas. For data-dependent $\mathrm{MS}^{n}$ analysis, the most abundant ions exceeding the threshold of $5 \times 10^{3}$ were isolated using an isolation width of $2 \mathrm{Th}$ and the predominant monoisotopic peak was selected for collision-induced dissociation (CID) experiments. The data were obtained with a relative collision energy of $20 \%$ for both full MS (650 to $900 \mathrm{~m} / \mathrm{z}$ ) and $\mathrm{MS}^{2}$ (500 to $885 \mathrm{~m} / \mathrm{z}$ ). Data acquisition and reduction were carried out using Xcalibur software (version 1.2).

The analysis quantifies the daughter ions by comparing the response obtained with that of methanolic dilutions of a reference solution of okadaic acid (OA) provided by the IMB of the National Research Council (Halifax, Canada). The quantification limit was $0.05 \mu \mathrm{g} \mathrm{OA} \mathrm{g}^{-1}$ (fresh tissue). The mean value recorded on the certified reference material (NRC/CMR-DSPMUS-b) measured on 8 extracts, performed with the same procedure as for the samples, was $9.47 \pm 2.28 \mu \mathrm{g} \mathrm{OA} \mathrm{g}^{-1}$ for a certified value of $10.1 \pm 0.8 \mu \mathrm{g} \mathrm{g}^{-1}$. The OA recovery rate after the hydrolysis procedure performed on the certified reference material was $91 \%$.

Solid phase adsorption toxins tracking (SPATT). After thawing, the bags were rinsed and vigorously shaken to remove salts and water. The resin was eluted with $25 \mathrm{ml}$ methanol. After evaporating the solvent to dryness, the residue was re-suspended in $1 \mathrm{ml}$ methanol, from which $5 \mu \mathrm{l}$ were used for LC-MS analysis.

Statistics. All graphs (histograms and curves) were plotted with Excel software and $t$-tests were used to compare the means for biological parameters. Linear regression analysis and pairwise comparisons were analyzed with Statgraphic software (Centurion XV).

\section{Results}

\subsection{Food supply}

The chlorophyll $a$ concentration measurements in the tanks receiving the fodder algae revealed a retention rate between 75 and $92 \%$ for Ker06 and between 82 and $88 \%$ for Ker07 (tank A and tank B, respectively). We consider that this retention was strongly linked to mussel filtration. In the tanks without food, the chlorophyll $a$ concentrations recorded at the inlet and outlet flux remained below $0.05 \mu \mathrm{g} \mathrm{L}^{-1}$.

\subsection{Biological parameters}

Mussel mortality rates estimated from the total dead individuals recorded in the trays throughout the experiment did not exceed $4 \%$ of the total weight.

The evolution of the biological parameters, including weight, is shown for Ker06 and 07, respectively (Fig. 1).

Dry weight. For Ker06, a loss of dry weight was recorded in the unfed mussels ( $t$-test, $p<0.001$ ), whereas biomass was stable in the fed mussels ( $t$-test, $p>0.05$, Fig. 1a). For Ker07, a significant difference in mass was observed between the beginning and the end of the trial for the three food levels $(t$-test, $p<0.001$ ), corresponding to increases of 14,15 and $18 \%$ for the tank without food, tank A (low food level) and tank B (high food level), respectively (Fig. 1b). The increase of dry matter in the unfed mussels of Ker07 is a surprising result for the chlorophyll $a$ measures revealed the absence of chlorophyllic organisms. However, we cannot be sure that the media was completely free of organic matter, as this was not verified.

Lipid and glycogen. For Ker06 (Fig. 1a), the total lipid concentrations decreased in the unfed mussels $(p<0.05)$ but remained at a level equivalent to the initial level in the fed mussels $(t$-test, $p>0.1)$. The glycogen concentrations did not vary significantly between the beginning and the end of this trial in either of the tanks ( $p>0.05$ ). For Ker07 (Fig. 1b), the lipid concentrations showed a tendency to increase in the tanks receiving food but the increase was not significant $(p>0.05)$ whereas the glycogen concentrations differed between the start and the end of the trial in the control tank and in tank B $(p<0.05)$.

\subsection{Toxin evolution in the digestive gland}

The residual meat, after digestive gland removal, was checked for the presence of toxins several times during the trials (T0, T8, T10 and T21) but no toxins were detected. Therefore, only toxin concentrations in digestive gland will be considered. Firstly, decontamination kinetics according the different food levels were compared distinguishing free OA, measured in non hydrolysed extracts, and total OA, measured in hydrolysed extracts. The concentrations of different kinds of ester that may be accumulated or produced by mussels (diol or acyl-esters) were estimated by the difference between the total and free OA concentrations. Secondly, depuration rates between esters and free OA were compared, depuration rate being defined as the percentage of concentration decrease obtained between the start and the end of the experiment.

Ker06 trial. The concentration evolution over time was established separately for free OA and total OA (Fig. 2). An overall examination of the relationships suggests two phases.

- Over the course of the first few days, not only was the decontamination not visible, but an increase in OA concentration occurred, except for free OA in the tank receiving the food, which remained stable.

- After the third day,the OA concentrations seemed to follow a linear decrease over time (Table 1). In fact, disregarding the values of the first two days, the linear relationships were significant in both food levels $(p<0.001)$. The comparison of the regression slopes obtained for fed and unfed mussels illustrated the divergent behaviour of the two forms of the toxin. For free OA, the kinetics were very similar $(p=0.553)$. For total OA, they differed significantly $(p<0.001)$ indicating a faster elimination by the fed mussels than the unfed ones. After three weeks, the total OA depuration rate reached $90 \%$ in the fed mussels whereas it was only $52 \%$ in the unfed mussels.

Ker07 Trial. In this second trial, an additional food level was introduced and the number of sampling days was reduced to maintain a practical work load. The toxin evolution over 
KER 06
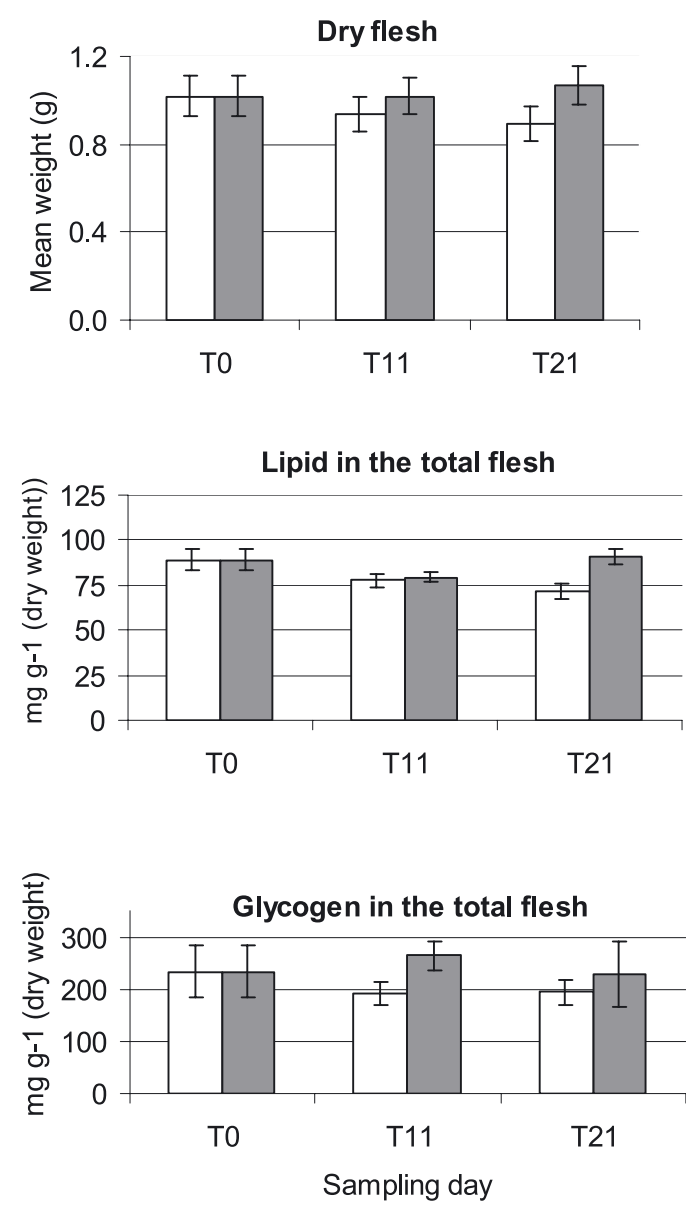

$\square$ Without food $\square$ With food
KER 07
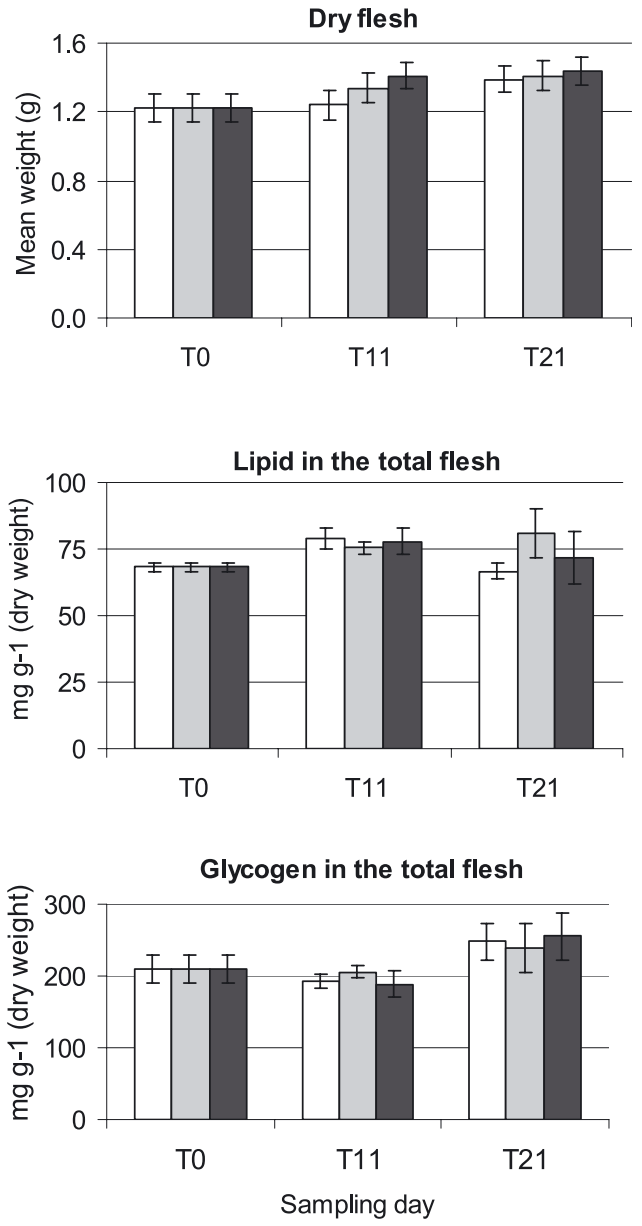

$\square$ Without food $\square$ Food A $\square$ Food B

Fig. 1. Evolution of total flesh mass in mussels, Mytilus edulis, from South Brittany in 2006 and 2007 (a: Ker06 and b: Ker07), and the concentrations of lipid and glycogen in the total flesh. Vertical bars indicate 5\% confidence intervals of means $(n=9)$.

time in the three tanks is displayed (Fig. 3). The free or total OA concentration decrease was more rapid in presence of food. Moreover, OA elimination (free or total) was quicker when diatom supply was greater (in tank B). In contrast to Ker06, the whole shape of the relationships between the concentrations and time fitted better with a decreasing exponential curve for both toxin groups than it did with a linear relation (data not shown). From the same dataset, the log-transformed concentration over time was established for regression analysis for each food level and toxin form (free and esterified OA, Fig. 4). The regression analysis (Table 2) indicated that each relationship fitted significantly with a linear model $(p<0.001)$ and pairwise comparison between fed and unfed and between fed $\mathrm{A}$ and fed B, showed that there was a significant difference in the slopes between the three food levels $(p<0.01$ whatever pair was examined). Decontamination speed is therefore enhanced by the food supply for free OA and total OA. On the other hand, there was no significant difference in slope coefficients between free OA and total OA $(p>0.05)$ for food level, which is different from results seen in 2006.
Table 1. Ker06: main parameters of simple linear regressions between the okadaic acid $(\mathrm{OA})$ concentrations and time estimated from fed and unfed mussels: the slope and its $95 \%$ confidence interval (CI), the square of correlation coefficient $\left(R^{2}\right)$ and the time in days to reach a $50 \%$ reduction in toxin concentration (half-life), calculated according to the regression equation.

\begin{tabular}{lcccc}
\hline Ker 06 & & $R^{2}$ & $\begin{array}{c}\text { Slope } \\
95 \% \text { CI }\end{array}$ & $\begin{array}{c}\text { Half-life } \\
\text { (day) }\end{array}$ \\
\hline \multirow{3}{*}{ Without food } & Free OA & 0.64 & -0.289 & 14 \\
& & & $-0.405-0.174$ & \\
\cline { 2 - 5 } & Total OA & 0.70 & -0.342 & 20 \\
& Free OA & 0.83 & $-0.459-0.225$ & \\
\hline \multirow{3}{*}{ With food } & & & -0.429 & 11 \\
& Total OA & 0.90 & -0.612 \\
& & & $-0.724-0.501$ & 11 \\
\hline
\end{tabular}

A dry weight increase of the total flesh, from 14 to $18 \%$, was recorded in the Ker07 experiment. Consequently, a toxin 

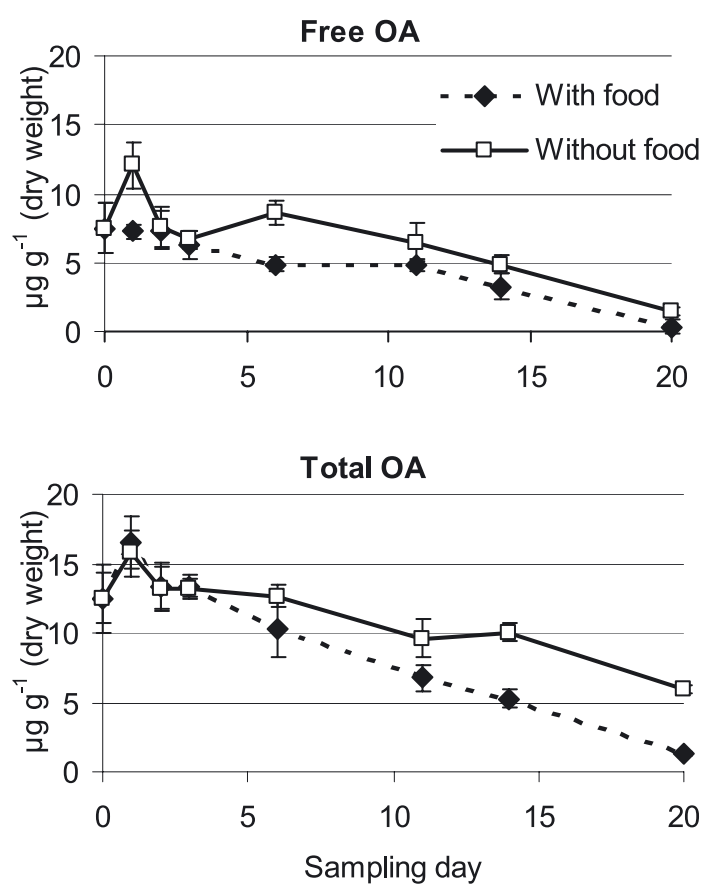

Fig. 2. Ker06: evolution of diarrhetic shellfish toxins (DST concentrations) in digestive glands of fed and unfed mussels. Vertical bars indicate standard deviation of 3 independent extracts.

dilution over time could be suspected. The kinetics were therefore established by expressing the toxicity in toxin burden (Log transformed quantity of OA per individual) and the same statistical analysis was applied to these new data. Table 2 shows the relevant parameters for these new regressions. The conclusions were the same: i) the linear relationship was highly significant $(p<0.05)$ for the three food conditions and both toxin groups; ii) there was a significant difference between the three food levels $(p<0.01)$ and the higher the food level, the more the elimination was accelerated. Toxin elimination is clearly established. After three weeks, the total OA depuration rate reached $78 \%$ and $89 \%$ in the fed mussels (tanks A and B, respectively) whereas it was only $61 \%$ in the unfed mussels.

Free $\mathrm{OA}$ and ester depuration rates. The initial ester concentrations before the experiment were $5 \mu \mathrm{g} \mathrm{g}^{-1}$ and $6.1 \mu \mathrm{g}$ $\mathrm{g}^{-1}$ DG dry weight for Ker06 and Ker07, respectively. Histograms show that the depuration rates of esters are systematically lower than those of free OA (Fig. 5). This is particularly clear in the tank without food in 2006 where ester depuration rate was $9 \%$ compared with $80 \%$ for free OA. The gap was much smaller in presence of fodder algae where the rate was $80 \%$ for esters and $96 \%$ for free OA. In 2007, although the ester depuration rate was higher than in 2006 in the tank without food $(49 \%$ versus $9 \%)$, it increased with the food level $(75 \%$ and $85 \%$ for $\mathrm{A}$ and $\mathrm{B}$, respectively).
Free OA

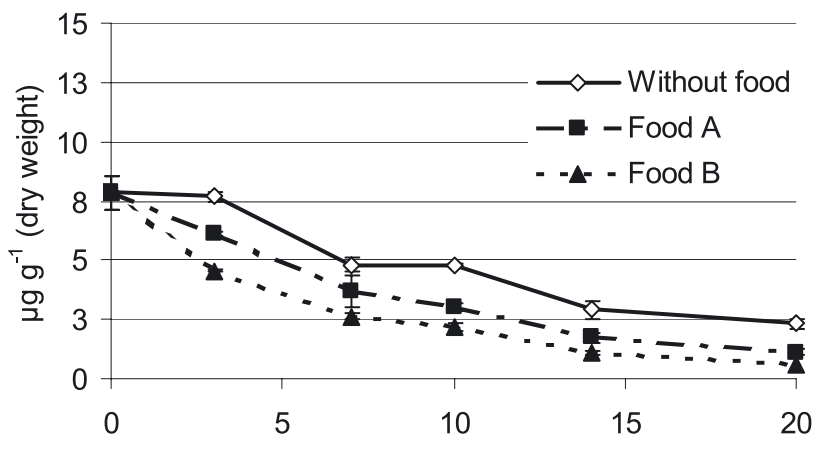

Total OA

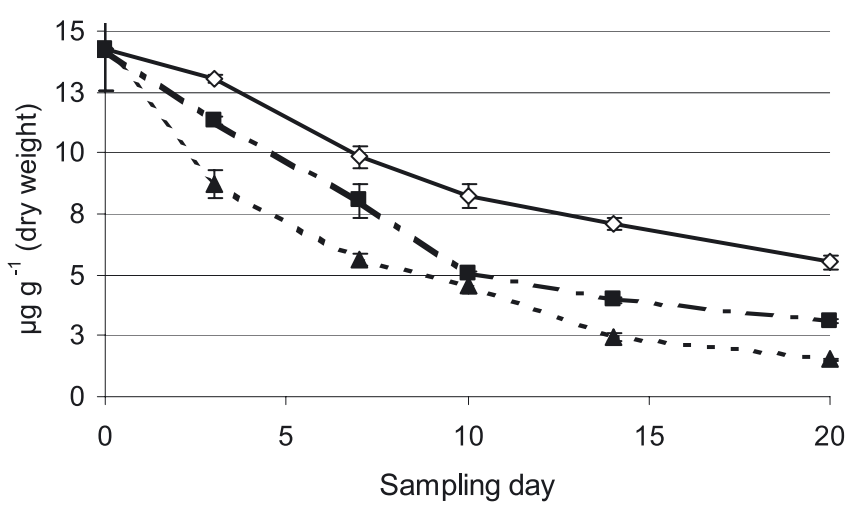

Fig. 3. Ker07: evolution of okadaic acid concentrations (free OA; total $\mathrm{OA}$ ) in the digestive gland over time. Error bars represent standard deviation of 3 independent extracts.

\subsection{Toxin detection in biodeposits and in the passive adsorption devices (SPATT bags)}

Quantities of biodeposits notably decreased over time in the tank without food, as was expected, while they increased in the tanks receiving food during the trial. In addition, in Ker07, the biodeposit quantity in tank B was around twice the amount in tank A. Although the amount of biodeposits could not be measured precisely, the OA concentrations per gram of dry weight revealed that OA was mainly detected in hydrolysed extracts (Fig. 6), suggesting that it would be released as esters. Free OA was, in fact, detected as traces in all cases except in the tank without food for Ker06, where the concentration reached around $15 \mu \mathrm{g} \mathrm{g}^{-1}$ dry weight. For this reason, only total OA evolution is shown in the diagram for tanks with food (Fig. 6). The same trend in the evolution of total OA concentrations was observed in both tanks, except in Ker06 in the tank without food. After an increase during the first days of the trials, values decreased from around the tenth day for Ker06 and the eighth day for Ker07.

Concerning the passive adsorption of OA on the resin bags, the results of the two trials differed notably (data not shown). No toxin or traces were detected in Ker06, while quantities measured in Ker07 were quite low and highly variable (from 0 to $95 \mathrm{ng}$ per bag), with no trend either over time or with food 
Table 2. Ker07: main information on the regression lines: log values for okadaic acid content over time are expressed as concentration (ln C, $\mu \mathrm{g} \mathrm{g}^{-1}$ digestive gland) or as toxin burden (ln Tb, ng per mussel). $R^{2}$ : square of coefficient correlation, $95 \%$ CI: Confidence interval of the slope, Half-life $\left(t_{1 / 2}\right)$ : the time in days to reach a $50 \%$ reduction in toxin concentration or toxin burden, calculated according to the equation: $t_{1 / 2}=\ln (1 / 2) k^{-1}$ where $k$ is the slope of the line.

\begin{tabular}{lccccccc}
\hline Ker 07 & & \multicolumn{3}{c}{ ln C } & \multicolumn{3}{c}{ ln Tb } \\
\cline { 2 - 7 } & $R^{2}$ & $\begin{array}{c}\text { Slope } \\
95 \% \text { CI }\end{array}$ & $\begin{array}{c}\text { Half-life } \\
\text { (day) }\end{array}$ & $R^{2}$ & $\begin{array}{c}\text { Slope } \\
95 \% \text { CI }\end{array}$ & $\begin{array}{c}\text { Half-life } \\
\text { (day) }\end{array}$ \\
\hline \multirow{2}{*}{ Without Food } & Free OA & 0.92 & $\begin{array}{c}-0.064 \\
-0.069-0.054\end{array}$ & 10.9 & 0.93 & $\begin{array}{c}-0.075 \\
-0.080-0.070\end{array}$ & 9.2 \\
\cline { 2 - 7 } & Total OA & 0.95 & $\begin{array}{c}-0.048 \\
-0.051-0.045\end{array}$ & 14.7 & 0.95 & $\begin{array}{c}-0.059 \\
-0.063-0.056\end{array}$ & 11.9 \\
\hline \multirow{3}{*}{ Food A } & Free OA & 0.96 & $\begin{array}{c}-0.096 \\
-0.101-0.091\end{array}$ & 7.2 & 0.97 & $\begin{array}{c}-0.104 \\
-0.108-0.099\end{array}$ & 7.6 \\
\cline { 2 - 7 } & Total OA & 0.94 & $\begin{array}{c}-0.078 \\
-0.083-0.07\end{array}$ & 9.0 & 0.95 & $\begin{array}{c}-0.086 \\
-0.090-0.080\end{array}$ & 8.2 \\
\hline \multirow{3}{*}{ Food B } & Free OA & 0.98 & $\begin{array}{c}-0.124 \\
-0.128-0.120\end{array}$ & 5.6 & 0.98 & $\begin{array}{c}-0.132 \\
-0.136-0.127\end{array}$ & 5.7 \\
\cline { 2 - 7 } & Total OA & 0.97 & $\begin{array}{c}-0.107 \\
-0.112-0.103\end{array}$ & 6.5 & 0.98 & $\begin{array}{c}-0.115 \\
-0.119-0.111\end{array}$ & 6.6 \\
\hline
\end{tabular}
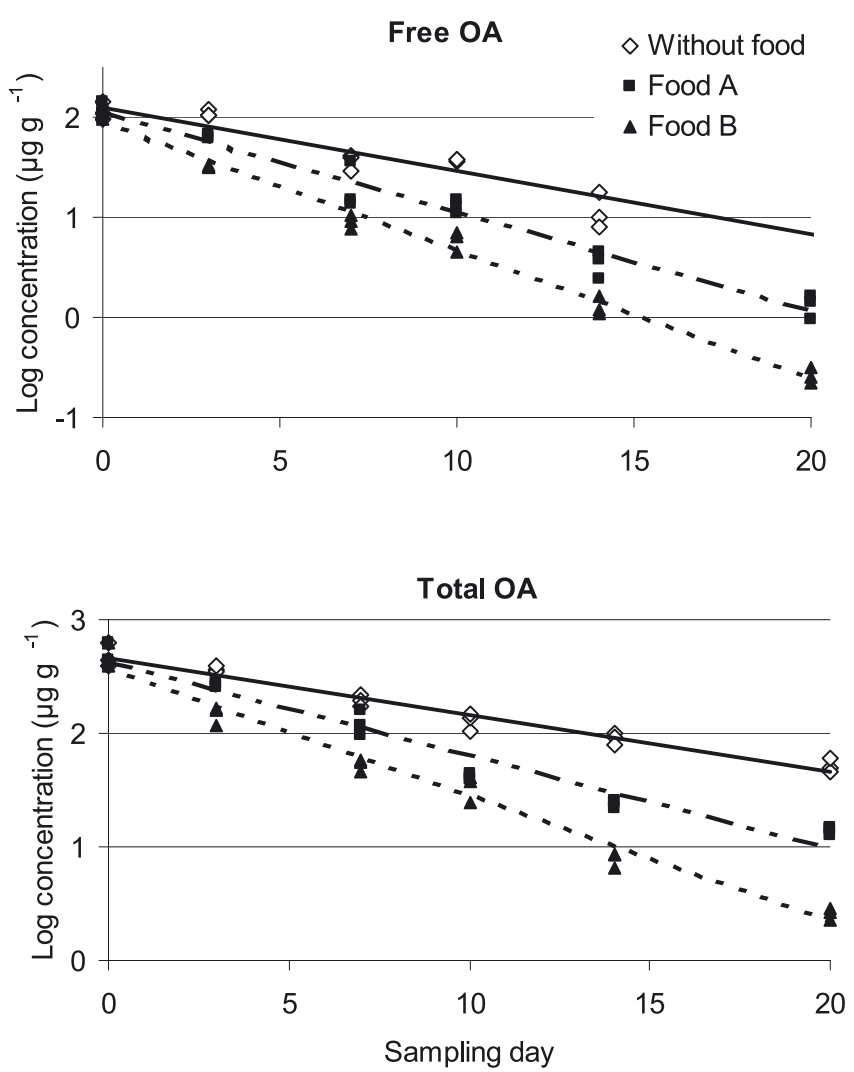

Fig. 4. Ker07: relationships of Log transformed concentrations of okadaic acid (free OA; total OA ) with time for the different levels of food. The regression parameters are summarised in Table 2.

level. These amounts of adsorbed toxin are low in comparison with the adsorption capability of polymeric resin for OA (Fux et al. 2008).

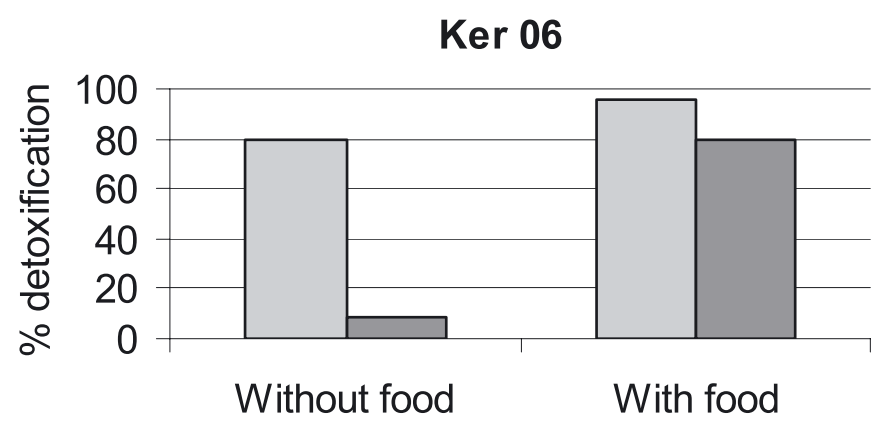

Ker 07

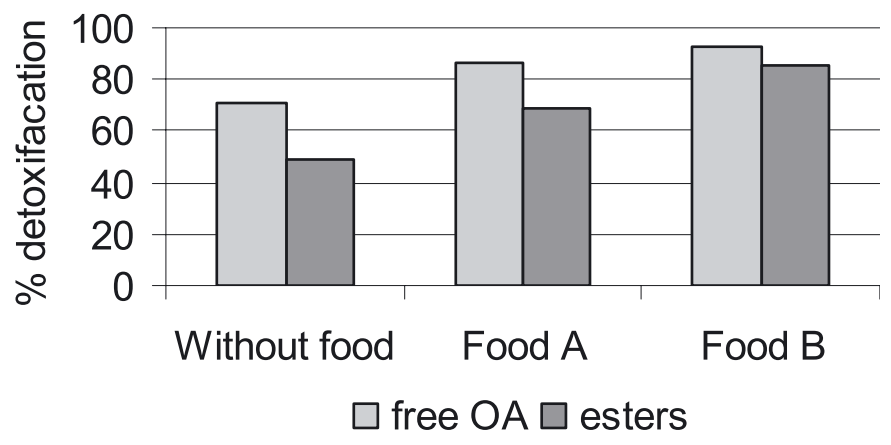

Fig. 5. Ker06 and Ker07: percentage of detoxification calculated from the difference between the concentrations at the start and the end of the trial for each food level. Ester concentrations were given by the difference between total- and free okadaic acid (OA).

\section{Discussion}

The low mortality rate reflects the appropriateness of the experimental facilities for the maintenance of $\sim 100 \mathrm{~kg}$ of live mussels in good condition. The high retention rate of diatom cells, the stability of the dry flesh weight in 2006 and its 
Tank without food

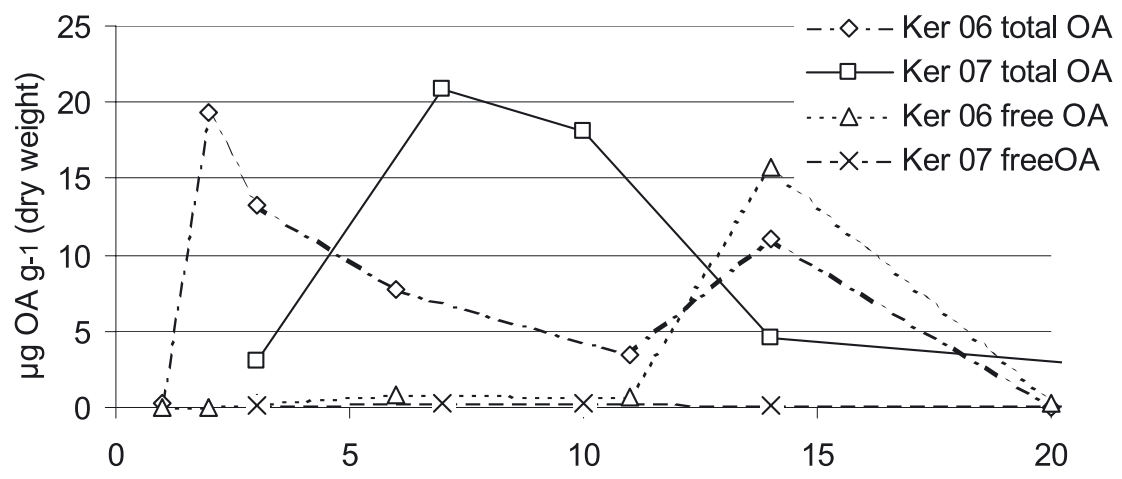

Tank with food

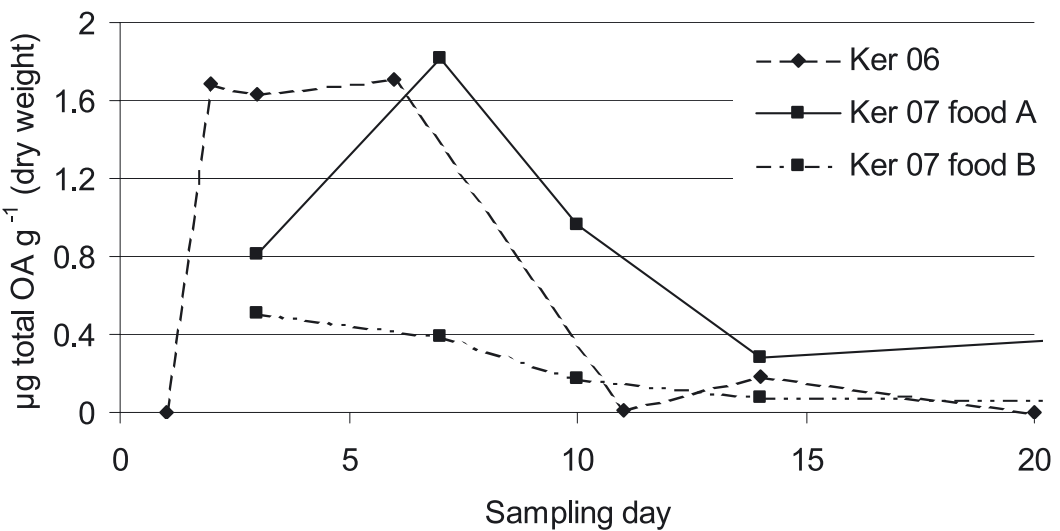

Fig. 6. Ker06 and Ker07: evolution of okadaic acid concentrations in biodeposit for both trials for the tanks without (top) and with food (down), shown separately. Only total OA is plotted in the diagram corresponding to the tank with food because, free OA was not detected or only detected as traces in this tank. As total biodeposits were not quantified, this figure gives information on the nature and the relative level of toxins over time.

increase in 2007 demonstrate that the mussels fed on the fodder algae. Moreover, the biochemical parameters confirmed this observation overall. The increase of mean dry weight in the unfed mussels of Ker07 can be explained by the presence of organic matter in the water which may have been more important in Ker07 than in Ker06. Nevertheless, the expected loss of dry matter is not systematically observed in previous studies either. For example, the monitoring of digestive gland weights during comparable decontamination studies has either shown stability until the sixteenth day (Svensson 2003) or a trend towards a rise recorded on the twenty-fourth day of experimentation (Svensson and Förling 2004).

Concerning the mussel contamination, the similarity in the initial toxicity of mussel batches used for both trials was a coincidence. The initial rates of esters, at $40 \%$ and $42 \%$ for Ker06 and Ker07, respectively, ( $\sim 5$ to $6 \mu \mathrm{g} \mathrm{g}^{-1} \mathrm{DG}$, dry weight). These values are comparable to those obtained in the literature (Suzuki and Mitsuya 2001; Vale et al. 2002; Torgersen et al. 2008), using the same procedure to measure the total OA from the initial methanolic phase after a hydrolysis step. In this way, all esterified OA derivatives are taken into account.
For both trials, the comparison of OA concentration over time, whether it be as free acid or in esterified form, showed a positive effect of food supply on decontamination rate of mussels. This effect was even greater when the food input was high. Moreover, in the case of Ker07, where an increase in the dry flesh was recorded after three weeks, the same comparison carried out from values expressed as individual toxin burden - taking into account a possible dilution effect - highlighted that it is not due to a tissue dilution. These results contrast with those published by Svensson (2003) who did not observe a significant difference between food rations and concluded that OA depuration was not positively influenced by digestive activity. Nevertheless, the high residual variability reported in this previous study could explain why a food effect was not visible.

The fact that the ester depuration rates were lower than those of free OA suggests that esters would reduce the elimination of total OA, as shown in the comparison between free and total OA kinetics. Additionally, the difference between the depuration rates of free $\mathrm{OA}$ and esters tended to diminish as the food supply increased, suggesting that food acts on ester elimination. The high proportion of total OA revealed 
by biodeposit analysis with the low adsorption of OA in the resin bags reinforces this hypothesis.

This difference of behaviour according to toxin chemical structure was well demonstrated in the results of Ker06, on one hand by a significant difference between free and total OA decontamination kinetics and on the other hand by the ester depuration rate that was only $9 \%$. In Ker07, the phenomenon was not proven statistically. Nevertheless, for each food supply, the time taken to reduce the total OA content by half was once again longer than for free OA, and the rates of ester detoxification remained lower than those for free OA. The slower elimination of esters was also previously proposed by other authors who attempted to model the detoxification of DTX-contaminated mussels by a theoretical approach (Fernández et al. 1998; Moroño et al. 2003). Torgersen et al. (2008) demonstrated that fatty acid esters, quantified after hydrolysis, depurate slower than their toxin parent. They reported a mean half-life of 17 days for free OA and 35 days for OA acyl esters in mussels (M. edulis). However, when they measured these acyl esters directly by liquid chromatography-tandem mass spectrometry (LC-MS/MS) and LC/MS ${ }^{2}$, they found that their half-life was reduced to 10 days compared to the half-life of free OA. These results suggest that ester depuration would depend on chemical structure of the acyl group attached to the OA molecule.

Although both of our experiments were very similar in their methodology, the kinetic models are different. For Ker06, the toxicity evolution over time fits well to a linear relationship after the first two values are discarded. During the first two days, one observes an unexpected increase in the OA concentration, except for free OA in the fed mussels. The same observation was reported by Svensson (2003) in mussels fed with the lowest ration tested and in unfed mussels. This author attributed the phenomenon to a loss of digestive gland mass. This reason cannot be put forward in our case because there was no significant weight loss during the first ten days in the unfed mussels. Moreover, total OA concentration also increased in the digestive glands of fed mussels, while their dry weight remained stable. This OA increase could be explained by the digestive gland dissection, however. This action would have eliminated other body parts that might have been retaining algal cells. The amount of toxins in these other tissues would therefore not be taken into account on day T0, but might be assimilated into the DG in the following few days in the live animals.

This apparent "over contamination" at an early stage of the decontamination has been already described (Marcaillou et al. 1993; Blanco et al. 1999). In a review, Blanco et al. (2005) proposed a model describing the evolution of OA and its derivatives over the course of decontamination. They attributed this phenomenon to a release of OA caused by the rapid hydrolysis of OA derivatives present in Dinophysis cells. Indeed, OA diol-esters have recently been discovered in Dinophysis cells (Susuki et al. 2004; Miles et al. 2006) and, as OA diol-esters are known to be rapidly hydrolysed either by phytoplanktonic esterases (Quilliam et al. 1996) or mussel enzymes (Miles et al. 2004), their presence can be the source of OA release during the early phase of the decontamination. The extent of the presence of toxic cells in the digestive gland depends on the environmental situation preceding sampling. It differs according to studies and could explain why this phenomenon is not systematically reported. It could also explain why there was a difference between the two kinetic models described in this study. For Ker07, the absence of sampling during the first two days prevents us from knowing whether residual contamination occurs. However, the free OA concentration recorded on the third day was slightly higher than the starting concentration, which may suggest that a residual contamination occurred. For this trial, the data set fits very well with a biphasic shape, largely used in models (reviewed by Blanco et al. 2005). The difference between the decontamination kinetics recorded in fed mussels (food B) and unfed mussels was particularly noteworthy on the third day.

From both experiments, the time required to reduce the concentration by half, with the diet provided, is around 6 to 7 days. This duration of half-life is close to the shortest values of semi-depuration times recorded by Blanco et al. (2005), but is lower than times reported by Torgersen et al. (2008) who found a half-life of 10 days for acyl-esters quantified individually and 17 days for free OA.

Nevertheless, in the conditions described here, from an initial contamination of around $950 \mu \mathrm{g} \mathrm{kg}^{-1}$ (fresh total meat), 18 and 14 days were necessary to reach the legal limit (160 $\mathrm{g} \mathrm{kg}^{-1}$ total flesh) in 2006 and 2007 (with the highest food level), respectively, whereas it was not reached at the end of the trials in the unfed treatments. In the natural area for both years in 2006 and 2007, the shellfish market was re-opened in the sixth week after the beginning of the experiments in accordance with the monitoring survey. Therefore, the potential for reducing the time during which these shellfish are unsafe for consumers has been clearly demonstrated by these two experiments conducted in consecutive years. This study also led to hypotheses that may pave the way for future investigations. The time required to reach the regulatory threshold may seem too long for such an experimental system to be considered economically viable. Further work is therefore needed to reduce this time, and should be guided by the possible effect of the diet on ester synthesis and/or elimination over the course of time.

Acknowledgements. This study was funded by BIOTOX project (EU FP6 $N^{\circ}$ 514074). The authors would like to thank the team of the Morbihan Pays de la Loire coastal laboratory.

\section{References}

Blanco J., Fernández M.L., Miguez A., Moroño A., 1999, Okadaic acid depuration in the mussel Mytilus galloprovincialis: one- and two-compartment model and the effect of environmental conditions. Mar. Ecol. Prog. Ser. 176, 153-163.

Blanco J., Moroño A., Fernández M.L., 2005, Toxic episodes in shellfish, produced by lipophilic phycotoxins: an overview. Rev. Gal. Recur. Mariños (Monogr.) 1, 1-70.

Bligh E.G., Dyer W.J., 1959, A rapid method for total lipid extraction and purification. Can. J. Biochem. Physiol. 37, 911-917.

Dahl E., Yndestad M., 1985, Diarrhetic shellfish poisoning (DSP) in Norway in the autumn 1984 related to the occurence of 
Dinophysis spp. In: Anderson D., White A., Baden D.G. (Eds), Toxic dinoflagellates. Elsevier Science Publishing, pp. 495-500.

De Zwaan A., Mathieu M., 1992, Cellular biochemistry and endocrinology. In: Goslin, E. (Ed.), The mussel, Mytilus: ecology, physiology, genetics and culture. Elsevier Publishers B.V., Amsterdam, pp. 425-464.

Dubois F., Gille X.A., Hamilton J.K., Rebecs P.A., Smit F., 1956, Colorimetric method for determination of sugars and related substances. Anal. Chem. 28, 350-356.

Duinker A., Bergslien M., Strand O., Olseng C.D., Svardal A., 2007, The effect on size and age on depuration rates of diarrhetic shellfish toxins (DST) in mussels (Mytilus edulis L.). Harmful Algae $6,288-300$.

Edebo L., Lange S., Li X.P., Allenmark S., Lindgren K., Thompson R., 1988, Seasonal, geographic and individual variation of okadaic acid content in cultivated mussels in Sweden. Acta Pathol. Microbiol. Immunol. Scand. (APMIS) 96, 1036-1042.

Fernández, M.L., Míguez, A., Moroño, A., Cacho, E., Martínez, A., Blanco, J., 1998, Detoxification of low polarity toxins (DTX3) from mussels Mytilus galloprovincialis in Spain. In: Reguera B., Blanco J., Fernández M.L, Wyatt T. (Eds), Harmful Algae. Xunta de Galicia and Intergovernmental Oceanographic Commission of UNESCO.

Fux E., Marcaillou C., Mondeguer F., Bire R., Hess P., 2008, Field and mesocosm trials on passive sampling for the study of adsorption and desorption behaviour of lipophilic toxins with a focus on OA and DTX1. Harmful Algae 7, 574-583.

Haamer J., Andersson P.O., Lange S., Li X.P., Edebo L., 1990, Effects of transplantation and reimmersion of mussels Mytilus edulis Linnaeus, 1728, on their contents of okadaic acid. J. Shellfish Res. 9, 109-112.

Hu T., Doyle J., Jackson D., Marr J., Nixon E., Pleasance S., Quilliam M., Walter J., Wright J., 1992a, Isolation of a new diarrhetic shellfish from Irish mussels. J. Chem. Soc. 30, 39-41.

Hu T., Marr J., de Freitas A.S.W., Quilliam M.A., Walter J.A., Wright J.L.C., Pleasance S., 1992b, New diol esters of okadaic acid isolated from cultures of the dinoflagellates Prorocentrum lima and Prorocentrum concavum. J. Nat. Products 55, 1631-1637.

Lindahl O., Hageltorn M., 1986, Detoxification experiment of DSP in blue mussels. In: Proc. $4^{\text {th }}$ Nordic Veterinary Congress, Stockholm, pp. 463-466.

Lorenzen C.J., Jeffrey S.W., 1980, Determination of chlorophyll in seawater. UNESCO, Technical Paper in Marine Science $\mathrm{N}^{\circ} 35$.

MacKenzie L., Beuzenberg V., Holland P., McNabb P., Selwood A., 2004, Solid Phase Adsorption Toxin Tracking (SPATT): a new monitoring tool that simulates the biotoxin contamination of filter feeding bivalves. Toxicon 44, 901-918.

Marcaillou-Le Baut C., Bardin B., Bardouil M., Bohec M., Le Dean L., Masselin P., Truquet P., 1993, DSP depuration rates of mussels reared in a laboratory and an aquaculture pond. In: Smayda T., Shimitzu Y. (Eds), Toxic Phytoplankton Blooms in the sea. Elsevier, Amsterdam, pp. 531-536.

Marcaillou C., Mondeguer F., Gentien P., 2005, Contribution to toxicity assessment of Dinophysis acuminata (Dinophyceae). J. Appl. Phycol. 17, 155-160.

Marr J.C., Hu T., Pleasance S., Quilliam,M.A., Wright J.L.C., 1992, Detection of new 7-O-acyl derivatives of diarrhetic shellfish poisoning toxins by liquid chromatography-mass spectrometry. Toxicon 30, 1621-30.
Miles C.O., Wilkins A.L, Munday R., Dines M.H., Hawkes A.D., Briggs L.R., Sandvik M., Jensen D.J., Cooney J.M., Holland P.T., Quilliam M.A., MacKenzie A.L., Beuzenberg V., Towers N.R., 2004, Isolation of pectenotoxin-2 from Dinophysis acuta and its conversion to pectenotoxin-2 seco acid, and preliminary assessment of their acute toxicities. Toxicon 43, 1-9.

Miles C.O., Wilkins A.L., Hawkes A.D., Jensen D.J., Cooney J.M., Larsen K., Petersen D., Rise F., Beuzenberg V., MacKenzie A.L., 2006, Isolation and identification of a $\mathrm{cis}$ - $\mathrm{C}_{8}$-diol-ester of okadaic acid from Dinophysis acuta in New Zealand. Toxicon 48, 195203.

Mondeguer F., Rouland C., Mestres G., 2003, Validation d'un procédé automatisé d'extraction sur phase solide de glande digestive de moule pour l'identification et la quantification des Dinophysis toxines en LC/ESI/MS2 par piégeage d'ions quadripolaire. Rapp. Scient. Techn. Ifremer/ISTPM DEL/03.01 PN.

Mondeguer F., Genin E., Mestre G., Nsengiyumva C., 2004, Validation of an automated procedure of solid phase extraction of mussel digestive glands for identification and quantification of Dinophysis toxins in LC/ESI/MS2 by quadrupole ion trap. In: Proc. $5^{\text {th }}$ International Conference on Molluscan Shellfish Safety, Galway, 14-18 June 2004, pp. 94-99.

Moroño A., Arévalo F., Fernández M.L., Maneiro J., Pazos Y., Salgado C., Blanco J., 2003. Accumulation and transformation of DSP toxins in mussels Mytilus galloprovincialis during a toxic episode caused by Dinophysis acuminata. Aquat. Toxicol. 62, 269-280.

Murata M., Shimatani M., Sugitani,H., Oshima Y., Yasumoto T., 1982, Isolation and structural elucidation of the causative toxin of diarrhetic shellfish poisoning. Bull. Jpn. Soc. Sci. Fish. 48, 549552.

Poletti R., Viviani R., Casadei C., Lucentini L., Giannetti L., Funari E., Draisci R., 1996, Decontamination dynamics of mussels naturally contaminated with diarrhetic toxins relocated to a basin of the Adriatic Sea. In: Yasumoto T., Oshima Y., Fukuyo Y.(Eds.), Harmful and toxic algal blooms. Int. Oceanogr. Comm. UNESCO, pp. 429-432.

Quilliam M.A., Hardstaff W.R., Ishida N., McLachlan J.L., Reeves A.R., Rose N.W., Windust A.J., 1996, Production of diarrhetic shellfish poisoning (DSP) toxins by Prorocentrum lima in culture and development of analytical methods. In: Yasumoto T., Oshima Y., Fukuyo Y. (Eds.), Harmful and Toxic Algal Blooms, 7th International Conference on Toxic Phytoplankton. Int. Oceanogr. Comm. UNESCO, Senday, pp. 289-292.

Sidari L., Nichetto P., Cok S., Sosa S., Tubaro A., Honsell G., Della Logia R., 1998, Phytoplankton selection by mussels, and diarrhetic shellfish poisoning. Mar. Biol. 131, 103-111.

Suzuki S., Otab H., Yamasaki M., 1999, Direct evidence of transformation of dinophysistoxin-1 to 7-O-acyl-dinophysistoxin-1 (dinophysistoxin-3) in the scallop Pactinopecten yessoensis. Toxicon 37, 187-198.

Suzuki S., Mitsuya T., 2001, Comparison of dinophysistoxin-1 and esterified dinophysistoxin-1 (dinophysistoxin-3) contents in the scallop Patinopecten yessoensis and the mussel Mytilus galloprovincialis. Toxicon 39, 905-908.

Suzuki T., Beuzenberg V., Mackenzie L., Quilliam M.A., 2004, Discovery of okadaic esters in the toxic dinoflagellate Dinophysis acuta from New Zealand using liquid chromatography/tandem 
mass spectrometry. Rapid Comm. Mass Spectrom. 18, 11311138.

Suzuki T., Igarashi T., Ichimi K., Watai M., Suzuki M., Ogiso E., Yasumoto T., 2005, Kinetics of diarrhetic shellfish poisoning toxins, okadaic acid, dinophysistoxin-1, pectenotoxin-6 and yessotoxin in scallops Patinopecten yessoensis. Fish. Sci. 71, 948-955.

Svensson S., 2003, Depuration of okadaic acid (diarrhetic toxin) in mussels, Mytilus edulis (Linnaeus), feeding on different quantities of non-toxic algae. Aquaculture 218, 277-291.

Svensson S., Förlin L., 2004, Analysis of the importance of lipid breakdown for elimination of okadaic acid (diarrhetic shellfish toxin) in mussels, Mytilus edulis: results from a field study and a laboratory experiment. Aquat. Toxicol. 66, 405-418.

Torgersen T., Sandvik M., Lundve B., Lindegarth S., 2008, Profiles and levels of fatty acid esters of okadaic acid group toxins and pectenotoxins during toxin depuration. Part II: Blue mussels (Mytilus edulis) and flat oyster (Ostrea edulis). Toxicon 52, 418427.

Vale P., Sampayo M.A., 2002, Esterification of DSP toxins by Portuguese bivalves from the Northwest coast determined by LCMS a widespread phenomenon. Toxicon 40, 33-42.

Yanagi T., Murata M., Torigoe K., Yasumoto T., 1989, Biological activities of semisynthetic analogs of dinophysistoxin-3, the major diarrhetic shellfish toxin. Agric. Biol. Chem. 53, 525-529.

Yasumoto T., Oshima Y., Yamaguchi M., 1978, Occurrence of a new type of shellfish poisoning in the Tohoku district. Bull. Jpn. Soc. Sci.. Fish. 44, 1249-1255.

Yasumoto T., Murata M., Oshima Y., Sano M., Matsumoto G.K., Clardy J., 1985, Diarrhetic shellfish toxins. Tetrahedron 41, 1019-1025. 